Pacific Journal of Mathematic 


\title{
SPACE COVERINGS BY TRANSLATES OF CONVEX SETS
}

\author{
H. GROEMER
}

Let $\left(C_{i}\right)$ be a sequence of compact convex subsets of euclidean $n$-dimensional space $E^{n}$. Some necessary and sufficient conditions in order that almost all points of $E^{n}$ can be covered by translates of the sets $C_{i}$ are established. It is shown that such a covering is possible if and only if all points of $E^{n}$ can be covered by congruent copies of the sets $C_{i}$.

1. Introduction. Let $\left(C_{i}\right)=\left(C_{1}, C_{2}, \cdots\right)$ be a sequence of convex subsets of $n$-dimensional euclidean space $E^{n}$. We say that $\left(C_{i}\right)$ permits an isometric covering of $E^{n}$ if there are proper isometries (rigid motions) $\sigma_{1}, \sigma_{2}, \cdots$ so that $E^{n} \subset \cup \sigma_{i} C_{i}$. In [1], [2], [3], [4], [5], and [6] it has been shown that in many cases those sequences $\left(C_{i}\right)$ that permit isometric coverings of $E^{n}$ can be characterized in terms of convergence properties of sequences involving the volumes, diameters or other functionals associated with the sets $C_{i}$. Recently S. K. Stein has pointed out that analogous problems can be considered if instead of isometries only translations are permitted. In fact, already Hlawka [9] has proved some results involving this idea. A covering problem regarding translates of strips has been considered in [7]. Generally speaking, translative problems of this kind appear to be more difficult than the corresponding isometric ones. However, in the present paper it will be shown that the situation is a rather different one if, instead of translative coverings of all $E^{n}$, one considers translative coverings of almost all points of $E^{n}$ (with respect to Lebesgue measure). A sequence $\left(C_{i}\right)$ is said to permit a translative covering of almost all points of $E^{n}$ if there are translates $C_{1}^{\prime}, C_{2}^{\prime}, \cdots$ of $C_{1}, C_{2}, \cdots$ so that $E^{n} \backslash \cup C_{i}^{\prime}$ is a nullset. First, we establish some necessary and sufficient conditions in order that a given sequence $\left(C_{i}\right)$ permits such a covering of $E^{n}$ (Theorem 1 and corollaries). Then we are going to prove the rather unexpeced result that a sequence of compact convex subsets of $E^{n}$ permits a translative covering of almost all points of $E^{n}$ if and only if it permits an isometric covering of all $E^{n}$ (Theorem 2). Although these two covering properties are equivalent there exists apparently no direct procedure for obtaining the one kind of covering from the other.

In the following section two lemmas are proved. Our theorems together with proofs and corollaries are presented in the third 
section. $n$ denotes always an arbitrary but fixed positive integer.

2. Two lemmas. If $S \subset E^{n}, T \subset E^{n}$ we denote by $S+T$ the vector sum $\{s+t: s \in S, t \in T\}$. For $x \in E^{n}$ we write $S+x$ instead of $S+\{x\}$. Lebesgue measure in $E^{n}$ is denoted by $m$. The closed ball in $E^{n}$ of radius $r$ and with center at the origin is denoted by $U(r)$. Instead of $U(1)$ we write simply $U$. By $\kappa_{n}$ we denote the volume of $U$.

LEMma 1. Let $M_{1}$ and $M_{2}$ be two measurable subsets of $E^{n}$ such that $M_{1}$ is contained in a translate of $U\left(r_{1}\right)$ and $M_{2}$ in a translate of $U\left(r_{2}\right)$. Then, there exists a point $p \in E^{n}$ so that

$$
m\left(M_{1} \cap\left(M_{2}+p\right)\right) \geqq \frac{1}{\kappa_{n}\left(r_{1}+r_{2}\right)^{n}} m M_{1} m M_{2} .
$$

Proof. We can certainly assume that $m M_{1} \neq 0, m M_{2} \neq 0$ and $M_{1} \subset U\left(r_{1}\right), M_{2} \subset U\left(r_{2}\right)$. If $m$ is viewed as a Haar measure on the translation group of $E^{n}$ it is a well-known result of measure theory (cf. Halmos [8], p. 261) that

$$
\int_{E^{n}} m\left(M_{1} \cap\left(M_{2}+x\right)\right) d x=m M_{1} m M_{2} .
$$

The integration in (1) can obviously be restricted to those points $x$ that satisfy $M_{1} \cap\left(M_{2}+x\right) \neq \phi$, which is equivalent to $x \in\{p-q$ : $\left.p \in M_{1}, q \in M_{2}\right\}$. Because of $M_{1} \subset U\left(r_{1}\right)$ and $M_{2} \subset U\left(r_{2}\right)$ it follows that the integration in (1) can be restricted to $U\left(r_{1}+r_{2}\right)$. Using this fact we deduce from (1) that

$$
\kappa_{n}\left(r_{1}+r_{2}\right)^{n} \sup _{x} m\left(M_{1} \cap\left(M_{2}+x\right)\right) \geqq m M_{1} m M_{2} .
$$

Here, if the equality sign would hold we could infer, taking also into account the assumption $m M_{1} m M_{2}>0$, that for almost all $y \in U\left(r_{1}+r_{2}\right)$

$$
m\left(M_{1} \cap\left(M_{2}+y\right)\right)=\sup _{x} m\left(M_{1} \cap\left(M_{2}+x\right)\right)>0 .
$$

But this relation is clearly not satisfied if $y$ belongs to a set of positive measure sufficiently close to the boundary of $U\left(r_{1}+r_{2}\right)$. Hence, (2) holds with strict inequality and this implies obviously Lemma 1.

To state our second lemma we need the following concepts which have also been used extensively in [3]. For $0 \leqq d \leqq n$ we denote by $\mathscr{C}^{d}$ the class of compact convex subsets of $E^{d}$. For $C \in \mathscr{C}^{d}$ let $D(C)$ be a line segment of maximal length that is contained in $C$. 
By $N(C)$ we denote the orthogonal projection of $C$ onto a $(d-1)$ flat that is orthogonal to $D(C)$. Furthermore, if $C \in \mathscr{C}^{n}$ we define

$$
\begin{aligned}
& N^{\circ}(C)=C \\
& N^{k}(C)=N\left(N^{k-1}(C)\right) \quad(k=1,2, \cdots, n),
\end{aligned}
$$

and

$$
D^{k}(C)=D\left(N^{k}(C)\right) \quad(k=0,1, \cdots, n) .
$$

Here $N^{j}(C)$ has to be viewed as a subset of an $E^{n-j}$. By a truncated $k$-cylinder we mean a set of form $K+I_{1}+I_{2}+\cdots+I_{n-k}$ where $K$ is a compact convex subset of a $k$-flat $H$, and $I_{1}, I_{2}, \cdots, I_{n-k}$ are mutually orthogonal compact line segments contained in an $(n-k)$-flat $H^{\perp}$ that is orthogonal to $H$. The analogously defined set $K+L_{1}+L_{2}+\cdots+L_{n-k}$ where $L_{1}, \cdots, L_{n-k}$ are mutually orthogonal lines in $H^{\perp}$ will be simply referred to as a $k$-cylinder. $K$ is called the base of the $k$-cylinder. Every truncated $k$-cylinder is compact and convex, every $k$-cylinder is closed and convex.

Lemma 2. Let $k$ be one of the integers $0,1, \cdots, n$ and $C \in \mathscr{C}^{n}$. If $Z$ is the truncated $(n-k)$-cylinder defined by

$$
Z=3^{-k} N^{k}(C)+3^{-1} D^{0}(C)+3^{-2} D^{1}(C)+\cdots+3^{-k} D^{k-1}(C)
$$

$(Z=C$ if $k=0)$ then there is a translate $Z^{\prime}$ of $Z$ so that

$$
Z^{\prime} \subset C \text {. }
$$

Proof. We prove the lemma by induction with respect to $k$. The case $k=0$ is trivial. If (3) is true for a given $k$ (and every $n$ ) it can be applied to $N(C)$ and we find that there is a translation vector $x$ so that

$$
3^{-k} N^{k+1}(C)+3^{-1} D^{1}(C)+\cdots+3^{-k} D^{k}(C)+x \subset N(C) .
$$

This implies obviously

$$
\begin{aligned}
3^{-(k+1)} N^{k+1}(C) & +3^{-1} D^{0}(C)+3^{-2} D^{1}(C)+\cdots \\
& +3^{-(k+1)} D^{k}(C)+x \subset \frac{1}{3}\left(N(C)+D^{0}(C)\right) .
\end{aligned}
$$

Hence (3) holds for $k+1$ if it can be shown that a translate of $1 / 3\left(N(C)+D^{\circ}(C)\right)$ is contained in $C$. However, this fact has been proved in [3] (Lemma 1).

3. Theorems. First we prove a theorem whose analogue for isometric coverings has been proved in [4]. The volume, considered 
as a functional on $\mathscr{C}^{d}$, will be denoted by $v_{d}$. But instead of $v_{n}$ we write often simply $v$; hence $v=m$ (the Lebesgue measure) on $\mathscr{C}^{n}$.

THEOREM 1. Let $\left(C_{i}\right)$ be a sequence of compact convex subsets of $E^{n}$ such that the sequence of the diameters of the sets $C_{i}$ is bounded. Then, $\left(C_{i}\right)$ permits a translative covering of almost all points of $E^{n}$ if and only if

$$
\sum v\left(C_{i}\right)=\infty
$$

Proof. Since (4) is obviously a necessary condition we have only to show that it is also sufficient. Moreover, it suffices to show that almost all points of the unit ball $U$ can be covered by translates of the sets $C_{i}$. The validity of this remark follows from the fact that $E^{n}$ can be written as a union of countably many unit balls, and that it is possible to partition the positive integers into infinitely many subsequences so that (4) holds for each corresponding subsequence of $\left(C_{i}\right)$ (for more details on this matter see the proof of Theorem 2 in [3]).

To prove that almost all points of $U$ can be covered we note first that there exists a number $r$ so that each $C_{i}$ is contained in some sphere of radius $r$. We show now inductively that there exist translates $C_{1}^{\prime}, C_{2}^{\prime}, \cdots$ of $C_{1}, C_{2}, \cdots$ so that for every positive integer $k$

$$
m\left(U \backslash \bigcup_{i=1}^{k} C_{i}^{\prime}\right) \leqq \kappa_{n} \prod_{i=1}^{k}\left(1-c m C_{i}\right)
$$

where $c=1 /\left(\kappa_{n}(1+r)^{n}\right)$. An application of Lemma 1 to the case $M_{1}=U, M_{2}=C_{1}, r_{1}=1, r_{2}=r$ yields a set $C_{1}^{\prime}=C_{1}+p$ so that

$$
m\left(U \cap C_{1}^{\prime}\right) \geqq c m U m C_{1} \text {. }
$$

This shows that

$$
m\left(U \backslash C_{1}^{\prime}\right) \leqq \kappa_{n}\left(1-c m C_{1}\right),
$$

which is (5) for $k=1$. If $C_{1}^{\prime}, C_{2}^{\prime}, \cdots, C_{k}^{\prime}$ have already been constructed so that (5) holds we apply again Lemma 1 , this time with $M_{1}=$ $U \backslash \bigcup_{i=1}^{k} C_{2}, M_{2}=C_{k+1}, r_{1}=1, r_{2}=r$. Then we obtain a set $C_{k+1}^{\prime}=$ $C_{k+1}+p$ so that

$$
m\left(\left(U \backslash \bigcup_{i=1}^{k} C_{i}^{\prime}\right) \cap C_{k+1}^{\prime}\right) \geqq c m\left(U \backslash \bigcup_{i=1}^{k} C_{i}^{\prime}\right) m C_{k+1} .
$$

It follows that 


$$
m\left(\left(U \backslash \bigcup_{i=1}^{k} C_{i}^{\prime}\right) \backslash C_{k+1}^{\prime}\right) \leqq m\left(U \backslash \bigcup_{i=1}^{k} C_{i}^{\prime}\right)-c m\left(U \backslash \bigcup_{i=1}^{k} C_{i}^{\prime}\right) m C_{k+1} .
$$

Because of (5) this shows that

$$
m\left(U \backslash \bigcup_{i=1}^{k+1} C_{i}^{\prime}\right) \leqq \kappa_{n} \prod_{i=1}^{k+1}\left(1-c m C_{i}\right)
$$

which is (5) with $k$ replaced by $k+1$. Due to the fact that $m\left(U \backslash C_{1}^{\prime}\right)$ is finite and $m\left(U \backslash \bigcup_{i=1}^{k} C_{i}^{\prime}\right)$, considered as a sequence in $k$, is decreasing it follows from (5) that

$$
m\left(U \backslash \bigcup_{i=1}^{\infty} C_{i}^{\prime}\right) \leqq \kappa_{n} \prod_{i=1}^{\infty}\left(1-c m C_{i}\right) .
$$

Since (4) implies $\prod_{i=1}^{\infty}\left(1-c m C_{i}\right)=0$ we obtain from $m\left(U \backslash \bigcup_{i=1}^{\infty} C_{i}^{\prime}\right)=0$, which is the desired result.

Theorem 1 can be generalized if one considers for a given $k=1,2, \cdots, n$ a sequence of $k$-cylinders $Z_{i}=B_{i}+H_{i}$ where each $B_{i}$ is a compact convex subset of some $k$-flat $G_{i}$ in $E^{n}$, and $H_{i}$ is an $(n-k)$-flat orthogonal to $G_{i}$. The $k$-flats $G_{i}$ are not assumed to be parallel. If $Q_{i}$ is a unit cube in $H_{i}$ and if we define $Z_{i}^{*}=B_{i}+Q_{i}$ then $v\left(Z_{i}^{*}\right)=v_{k}\left(B_{i}\right)$. Therefore, if the sequence of the diameters of $B_{i}$ is bounded the condition $\sum_{i} v_{k}\left(B_{i}\right)=\infty$ is sufficient in order that $\left(Z_{i}^{*}\right)$, and consequently $\left(Z_{i}\right)$, permits a translative covering of almost all points of $E^{n}$. Conversely if such a covering, say $\left(Z_{i}^{\prime}\right)$, exists then $m\left(U(\boldsymbol{r}) \cap \mathbf{U}_{i} Z_{i}^{\prime}\right)=\kappa_{n} r^{n}$. But it is easily proved (see [3], Lemma 2) that for $k=1,2, \cdots, n$

$$
m\left(U(r) \cap Z_{i}^{\prime}\right) \leqq \kappa_{n-k} r^{n-k} v_{k}\left(B_{i}\right)
$$

$\left(\kappa_{0}=1\right)$. Hence,

$$
\kappa_{n} \boldsymbol{r}^{n}=m\left(U(\boldsymbol{r}) \cap \bigcup_{i} Z_{i}^{\prime}\right) \leqq \sum_{i=1}^{\infty} m\left(U(\boldsymbol{r}) \cap Z_{i}^{\prime}\right) \leqq \kappa_{n-k} \boldsymbol{r}^{n-k} \sum_{i=1}^{\infty} v_{k}\left(B_{i}\right) .
$$

If we let $r$ tend to infinity this implies $\sum_{i=1}^{\infty} v_{k}\left(B_{i}\right)=\infty$. Thus, we can state the following corollary.

Corollary 1. Let $k$ denote one of the integers $1,2, \cdots, n$, and let $\left(Z_{i}\right)$ be a sequence of $k$-cylinders $Z_{i}$ in $E^{n}$ whose bases $B_{i}$ have volume $v_{k}\left(B_{i}\right)$. Moreover, it is assumed that the sequence of the diameters of the sets $B_{i}$ is bounded. Then, $\left(Z_{i}\right)$ permits a translative covering of almost all points of $E^{n}$ if and only if

$$
\sum_{i=1}^{\infty} v_{k}\left(B_{i}\right)=\infty \text {. }
$$

In the case of 1 -cylinders $Z_{i}=B_{i}+H_{i}$ each set $Z_{i}$ is a strip 
(or "slab") consisting of all points between two parallel hyperplanes of distance $v_{1}\left(B_{i}\right)$. Again, for different subscripts $i$ the segments $B_{i}$ are not assumed to be parallel. We call $v_{1}\left(B_{i}\right)$ the width of $Z_{i}$ and denote it by $w_{i}$. The condition of Corollary 1 that the sequence of the diameters of $B_{i}$ be bounded is of no importance for strips. In the proof of the necessity of condition (8) the boundedness was not used. On the other hand, if (8) is satisfied there are two possibilities. If $w_{i}>1$ for only finitely many strips one can remove these strips from the given sequence without changing the validity of (8). But if $w_{i}>1$ for infinitely many strips, each of these strips $Z_{i}$ can be replaced by a strip contained in $Z_{i}$ and of width equal to 1 , again without disturbing (8). Hence, Corollary 1 yields the following result:

COROLLARY 2. If $\left(Y_{i}\right)$ is a sequence of strips of widths $w_{i}$, then $\left(Y_{i}\right)$ permits a translative covering of almost all points of $E^{n}$ if and only if $\sum w_{i}=\infty$.

The problem regarding translative coverings of all $E^{n}$ by strips is much more difficult. In [7] it has been shown that for $n=2$ the condition $\sum w_{i}^{3 / 2}=\infty$ is sufficient.

We can now prove our main theorem concerning the relationship between isometric coverings of all $E^{n}$ and translative coverings of almost all points of $E^{n}$.

THEOREM 2. A sequence $\left(C_{i}\right)$ of compact convex subsets of $E^{n}$ permits a translative covering of almost all points of $E^{n}$ if and only if it permits an isometric covering of $E^{n}$.

Proof. It can be assumed that $C_{i} \neq \phi$ for all $C_{i}$. We use the projections $N^{k}(C)$ and the diameter sets $D^{k}(C)$ that have been used in Lemma 2. Moreover, for $k=0,1, \cdots, n$ we denote for any nonempty $C \in \mathscr{C}^{n}$ the diameter of $N^{k}(C)$ by $d^{k}(C)$, and define $v^{n}(C)=1$, $v^{k}(C)=v_{n-k}\left(N^{k}(C)\right)(k=0,1, \cdots, n-1)$. As in [3] we introduce also classes $S^{k}$ consisting of sets $C_{i}$ by

$$
\begin{aligned}
& S^{0}=\left\{C_{i}: d^{0}\left(C_{i}\right) \leqq 1\right\} \\
& S^{k}=\left\{C_{i}: d^{k}\left(C_{i}\right) \leqq 1, d^{k-1}\left(C_{i}\right)>1\right\} \quad(k=1,2, \cdots, n) .
\end{aligned}
$$

It has been shown in [3] (Theorem 2) that $\left(C_{i}\right)$ permits an isometric covering of $E^{n}$ if and only if there is an integer $k(0 \leqq k \leqq n)$ so that

$$
\sum_{C_{i} \in S^{k}} v^{k}\left(C_{i}\right)=\infty .
$$


Hence, our theorem is proved if we can show that $\left(C_{i}\right)$ permits a translative covering of almost all points of $E^{n}$ if and only if (9) holds.

Let us first assume that (9) is satisfied. It follows from Lemma 2 that each $C_{i} \in S^{k}$ contains a truncated $(n-k)$-cylinder $Z_{i}$ that is a translate of $3^{-k} N^{k}\left(C_{i}\right)+3^{-1} D^{0}\left(C_{i}\right)+\cdots+3^{-k} D^{k-1}\left(C_{i}\right)$. Because of $C_{i} \in S^{k}$ we have $d^{k-1}\left(C_{i}\right) \geqq 1$ and this implies that the length of each of the segments $D^{\circ}\left(C_{i}\right), D^{1}\left(C_{i}\right), \cdots, D^{k-1}\left(C_{i}\right)$ is at least 1. It follows that every $C_{i} \in S^{k}$ contains a translate of a truncated $(n-k)$-cylinder $T_{i}$ of the form $T_{i}=3^{-k}\left(N^{k}\left(C_{i}\right)+Q_{i}\right)$ where $Q_{i}$ is a $k$-dimensional unit cube. Since $C_{i} \in S^{k}$ implies also that the diameter of each $N^{k}\left(C_{i}\right)$ is not greater than 1 it follows that the sequence of the diameters of the cylinders $T_{i}$ is bounded. Taking into account that the volume of $T_{i}$ is $3^{-k n} v^{k}\left(C_{i}\right)$ we deduce from (9) and Theorem 1 that the sets $C_{i}$ from $S^{k}$ permit a translative covering of almost all points of $E^{n}$.

Let us now suppose that $\left(C_{i}\right)$ permits a translative covering of almost all points of $E^{n}$. We may assume that the sets $C_{i}$ have already been so translated that

$$
m\left(E^{n} \backslash \cup C_{i}\right)=0 .
$$

If $k=0,1, \cdots, n-1$ and $C_{i} \in S^{k}$ we note that $C_{i}$ is contained in an $(n-k)$-cylinder of the form $X_{i}=N^{k}\left(C_{i}\right)+L$ where $L$ is a $k$-flat orthogonal to $N^{k}\left(C_{i}\right)$. To each $X_{i}$ with $C_{i} \in S^{k}$ we may apply (7) (replacing the $k$-cylinders $Z_{i}^{\prime}$ by the $(n-k)$-cylinders $\left.X_{i}\right)$ which yields

$$
m\left(U(r) \cap X_{i}\right) \leqq r^{k} \kappa_{k e} v^{k}\left(C_{i}\right) \quad(k=0,1, \cdots, n-1) .
$$

From this and (10) we can deduce that

$$
\begin{aligned}
\kappa_{n} r^{n n} & =m\left(U(r) \cap\left(\bigcup_{C_{2} \in S^{n}} X_{i} \cup{\underset{C}{C_{i} \in S^{n}}} C_{i}\right)\right) \\
& \leqq \sum_{k=0}^{n-1} r^{k} \kappa_{k} \sum_{C_{i} \in S^{k}} v^{k}\left(C_{i}\right)+\sum_{C_{i} \in S^{n}} v\left(C_{i}\right) .
\end{aligned}
$$

For $r \rightarrow \infty$ it follows that (9) holds for some $k=0,1, \cdots, n-1$ or that $\sum_{\sigma_{i} \in S^{n}} v\left(C_{i}\right)=0$. In the latter case the class $S^{n}$ must be infinite and this implies $\sum_{C_{i} \in S^{n}} v^{n}\left(C_{i}\right)=\infty$. Hence, (9) holds for some $k=0,1, \cdots, n$, and we have obtained the desired conclusion.

As a consequence of Theorem 2 we can transfer all the necessary and sufficient conditions stated in [3] to translative coverings. We mention only the following result:

A sequence $\left(C_{i}\right)$ with $C_{i} \in \mathscr{C}^{n}$ permits a translative covering of almost all points of $E^{n}$ if and only if 


$$
\sum_{i=1}^{\infty} \frac{v\left(C_{i}\right)}{v\left(C_{i}+U\right)-v\left(C_{i}\right)}=\infty .
$$

\section{REFERENCES}

1. G. D. Chakerian, Covering space with convex bodies, Lecture Notes in Math., Vol. 490, The geometry of metric and linear spaces. Mich., 1974, Springer-Verlag, (1975), 187-193.

2. G.D. Chakerian and H. Groemer, On classes of convex sets that permit plane coverings, Israel J. Math., 19 (1974), 305-311.

3 . 77-86. , On coverings of euclidean space by convex sets, Pacific J. Math., 75 (1978),

4. H. Groemer, On a covering property of convex sets, Proc. Amer. Math. Soc., 59 (1976), 346-352.

5. , Some packing and coverings problems, Amer. Math. Monthly, 83 (1976), 726-727.

6. __ On finite classes of convex sets that permit space coverings, Amer. Math. Monthly, (in print).

7. _ On coverings of plane convex sets by translates of strips, (to appear).

8. P. R. Halmos, Measure theory, D. Van Nostrand, Princeton, N. J., 1950.

9. E. Hlawka, Ausfüllung und Überdeckung konvexer Körper durch konvexe Körper, Monatsh. Math., 53 (1949), 81-131.

Received November 1, 1978. Supported by National Science Foundation Research Grant MCS 76-06111 A01.

The University of Arizona

TUSCON, AZ 85721 


\section{PACIFIC JOURNAL OF MATHEMATICS}

\section{EDITORS}

Donald BABBITT (Managing Editor)

University of California

Los Angeles, CA 90024

HUGo RossI

University of Utah

Salt Lake City, UT 84112

C. C. MOORE and ANDREW OGG

University of California

Berkeley, CA 94720

\section{J. DuGUNDJI}

Department of Mathematics

University of Southern California

Los Angeles, CA 90007

R. FINN and J. Milgram

Stanford University

Stanford, CA 94305

ASSOCIATE EDITORS
E. F. BECKENBACH
B. H. NeumanN
F. WOLF
K. YoSHIDA

\section{SUPPORTING INSTITUTIONS}

\author{
UNIVERSITY OF BRITISH COLUMBIA \\ CALIFORNIA INSTITUTE OF TECHNOLOGY \\ UNIVERSITY OF CALIFORNIA \\ MONTANA STATE UNIVERSITY \\ UNIVERSITY OF NEVADA, RENO \\ NEW MEXICO STATE UNIVERSITY \\ OREGON STATE UNIVERSITY \\ UNIVERSITY OF OREGON
}

\author{
UNIVERSITY OF SOUTHERN CALIFORNIA \\ STANFORD UNIVERSITY \\ UNIVERSITY OF HAWAII \\ UNIVERSITY OF TOKYO \\ UNIVERSITY OF UTAH \\ WASHINGTON STATE UNIVERSITY \\ UNIVERSITY OF WASHINGTON
}

The Supporting Institutions listed above contribute to the cost of publication of this Journal, but they are not owners or publishers and have no responsibility for its content or policies.

Mathematical papers intended for publication in the Pacific Journal of Mathematics should be in typed form or offset-reproduced, (not dittoed), double spaced with large margins. Please do not use built up fractions in the text of the manuscript. However, you may use them in the displayed equations. Underline Greek letters in red, German in green, and script in blue. The first paragraph or two must be capable of being used separately as a synopsis of the entire paper. Please propose a heading for the odd numbered pages of less than 35 characters. Manuscripts, in triplicate, may be sent to any one of the editors. Please classify according to the scheme of Math. Reviews, Index to Vol. 39. Supply name and address of author to whom proofs should be sent. All other communications should be addressed to the managing editor, or Elaine Barth, University of California, Los Angeles, California, 90024.

50 reprints to each author are provided free for each article, only if page charges have been substantially paid. Additional copies may be obtained at cost in multiples of 50 .

The Pacific Journal of Mathematics is issued monthly as of January 1966. Regular subscription rate: $\$ 84.00$ a year (6 Vols., 12 issues). Special rate: $\$ 42.00$ a year to individual members of supporting institutions.

Subscriptions, orders for numbers issued in the last three calendar years, and changes of address should be sent to Pacific Journal of Mathematics, P.O. Box 969, Carmel Valley, CA 93924, U.S.A. Older back numbers obtainable from Kraus Periodicals Co., Route 100, Millwood, NY 10546.

PUBLISHED BY PACIFIC JOURNAL OF MATHEMATICS, A NON-PROFIT CORPORATION

Printed at Kokusai Bunken Insatsusha (International Academic Printing Co., Ltd.). 8-8, 3-chome, Takadanobaba, Shinjuku-ku, Tokyo 160, Japan.

Copyright (C) 1979 by Pacific Journal of Mathematics Manufactured and first issued in Japan 


\section{Pacific Journal of Mathematics}

\section{Vol. 82 , No. 2 \\ February, 1979}

Krishnaswami Alladi and Paul Erdős, On the asymptotic behavior of large prime

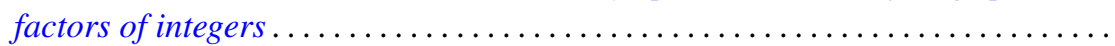

Alfred David Andrew, A remark on generalized Haar systems in $L_{p}$,

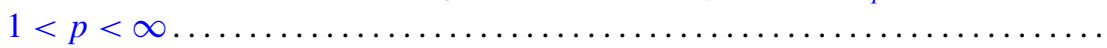

John M. Baker, A note on compact operators which attain their norm . . ........

Jonathan Borwein, Weak local supportability and applications to

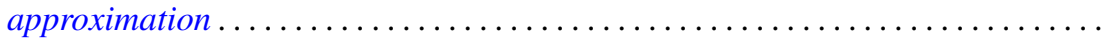

Tae Ho Choe and Young Soo Park, Wallman's type order compactification ........

Susanne Dierolf and Ulrich Schwanengel, Examples of locally compact

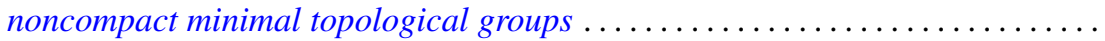

Michael Freedman, A converse to (Milnor-Kervaire theorem) $\times R$ etc. . . . . . . .

George Golightly, Graph-dense linear transformations ..................

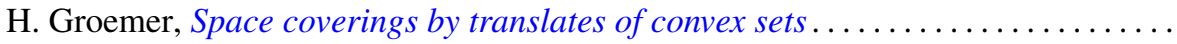

Rolf Wim Henrichs, Weak Frobenius reciprocity and compactness conditions in

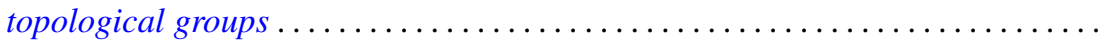

Horst Herrlich and George Edison Strecker, Semi-universal maps and universal

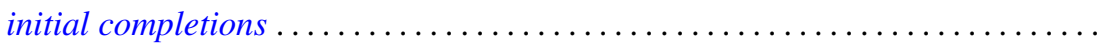

Sigmund Nyrop Hudson, On the topology and geometry of arcwise connected,

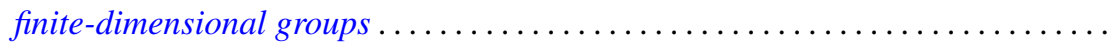

K. John and Václav E. Zizler, On extension of rotund norms. II .............

Russell Allan Johnson, Existence of a strong lifting commuting group of transformations. II.

Bjarni Jónsson and Ivan Rival, Lattice varieties covering the smallest nonmodular variety

Grigori Abramovich Kolesnik, On the order of Dirichlet L-functions .

Robert Allen Liebler and Jay Edward Yellen, In search of nonsolvable groups of

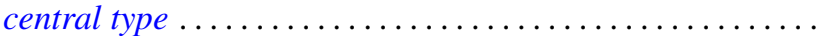

Wilfrido Martínez T. and Adalberto Garcia-Maynez Cervantes, Unicoherent plane Peano sets are $\sigma$-unicoherent ...

M. A. McKiernan, General Pexider equations. I. Existence of injective

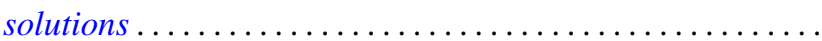

M. A. McKiernan, General Pexider equations. II. An application of the theory of webs.

Jan K. Pachl, Measures as functionals on uniformly continuous functions . .

Lee Albert Rubel, Convolution cut-down in some radical convolution algebras ...

Peter John Slater and William Yslas Vélez, Permutations of the positive integers

with restrictions on the sequence of differences. II . . .

Raymond Earl Smithson, A common fixed point theorem for nested spaces ....

Indulata Sukla, Generalization of a theorem of McFadden .... . . .

Jun-ichi Tanaka, A certain class of total variation measures of analytic measures.

Kalathoor Varadarajan, Modules with supplements .............. 